\title{
Enhancing Creative and Critical Thinking Skills of Students in Mathematics Classrooms: An Experimental Study of Teaching the Inequality in High Schools
}

\author{
Duong Huu Tong, ${ }^{1, *}$ Nguyen Phu Loc ${ }^{1}$, Bui Phuong Uyen ${ }^{1}$, Thach Hong Son ${ }^{2}$ \\ ${ }^{1}$ School of Education, Can Tho University, Vietnam \\ ${ }^{2}$ Can Tho University, Vietnam
}

Received November 12, 2019; Revised December 18, 2019; Accepted December 27, 2019

Copyright $\bigcirc 2020$ by authors, all rights reserved. Authors agree that this article remains permanently open access under the terms of the Creative Commons Attribution License 4.0 International License

\begin{abstract}
Teaching mathematics in high schools not only provides knowledge to solve problems or apply them into practice but also trains the students' ability to think mathematically. Therefore, in order to promote the students' mathematical thinking skills, teachers need to involve students in learning activities, help them train and develop their thinking. The purpose of this study was to enhance creative and critical thinking skills for 10th-grade students through teaching inequality topics. The experimental class had 41 students and was taught with activities of proving an inequality to enhance critical and creative thinking skills; while the control class consisted of 35 students and they approached conventionally. The qualitative method was used to evaluate students' creative and critical thinking skills for two types of exercises, namely, proving an inequality and finding the maximum value of a function. The findings showed that students in the experimental class showed a better ability to prove inequalities than students in the control class, and they also presented more solutions for a problem proving the inequality.
\end{abstract}

Keywords Creative and Critical Thinking, Inequality, Proving an Inequality, Mathematics Education

\section{Introduction}

Thinking is one of the categories of philosophy that reflects the attributes of the spirit, helping people to understand an object or phenomenon through improvement properly, change from feelings, from material activities, thereby behave positively. In particular, thinking from an educational perspective is the improvement of the brain to solve new problems, or to form a new knowledge based on the relationship as well as the improvement of the old, the known ones, thereby forming a new way of thinking that is more optimal with the old. Moreover, thinking can be understood as an activity of the cognitive process when facing a problem or solving a problem; there is an impact from the senses or the familiar ones stored in the brain. In favourable conditions and circumstances, thinking can be promoted effectively, so the problem is better solved.

Thinking in general and thinking in particular in teaching mathematics always have objects, which are needs objects [12]. The needs may be the need to discover new knowledge such as new concepts, new laws, new relationships, through conflict resolution, overcoming a cognitive obstacle, overcoming mistakes. Thus, to stimulate students' thinking, it is necessary to build situations containing obstacles, contradictions, related issues and formulate thinking for students to reveal problems in order to discover new knowledge, perceiving the new by the existing knowledge.

As we know, each subject has its unique characteristics. If the social sciences are about the memory, the feelings, the personal feelings of the writer, then the natural sciences require inquiry, thought, flexibility in problem-solving. Especially, mathematics is a primary subject which is the foundation of natural sciences and is one of the critical subjects in educational systems. Mathematics is put into the education system in countries at all levels from kindergarten to university because mathematics helps learners to practice the ability to think logically, become independent of thinking, be able to self-study and address problems. Mathematics is a relationship between specific problems expressed by one calculation or many calculations, so developing the capacity of mathematical thinking for students is a vital factor.

Mathematical competence is an expression of an individual's mathematical ability through acquiring 
knowledge, the ability to recognise meanings, roles, basic properties of mathematics as well as the use of that knowledge to solve problems. The application of existing knowledge is based on the activity of thinking such as analysing the problem, summarising the analysed ideas, comparing with similar knowledge, abstracting and generalising the problem to formulate methods for the problem called mathematical thinking skills. The ability of individual mathematical thinking is different because of the dependence on the ability to acquire knowledge, the ability to think, analyse, compare, abstract, generalise the problem effectively through shaping into assumptions and solve problems in diverse situations. For students in high schools, mathematical thinking capability is done through thinking manipulations such as comparison, analysis, synthesis, specialisation, generalisation, analogy, inductive and interpretation $[17,19]$.

In the trend of international integration, along with the development of science and technology, education has also gradually developed according to the trend of the era, along with that of human awareness, thereby raising a new height. When human awareness has raised to a new level, the capacity of thinking is no longer its nature but has developed in diversification ways of thinking, including creative thinking, one of the necessary competencies for thinking in the trend of the times. For high school students, developing creative thinking capacity is essential not only to help with their learning but also to create a premise for integration into society, thus meeting the needs of society.

Creative thinking is one of the activities of thought that is interested in researches from many domestic and foreign educators. Also, it is considered as a process of thinking based on what has been or formed from the knowledge relationship with reality, which results in creating something new. It is speculated that creative thinking leads to new knowledge about the world or about new modes of operation. Creative thinking is the process of seeking to perceive, discover the laws of things, consciously find new things to better understand the nature of things and phenomena as well as find the cause and prevent them, eliminate the unsuitable and develop the good. Thus, creative thinking is an essential attribute of human beings to exist and develop, inheriting and improving to promote good, useful and eliminating, preventing defective and harmful things for man.

When creative thinking starts, it produces a complex product, so it is an innovative, intuitive and continuous development and previous knowledge is synthesised and expanded to produce new ideas. Indeed, these new ideas are subject to analysis, criticism, and their effectiveness, which are considered in solving problems. Creative thinking creates the premise for the training and development of personality as well as intellectual capacity for students; promotes interest and learning needs; stimulates exploration and creativity [5]. On that basis, the introduction of some exercises will support students in utilising creative content knowledge and methods acquired in the learning process, so the level of expression of students' creative thinking capacity is shown through assessment of student's answer.

Creative thinking has several characteristics such as fluency, flexibility and originality [10]. The cleverness of thinking is expressed through the ability to collect information and data from details into the whole to form new hypotheses. Fluency is characterised by the ability to come up with new ideas from old ones, build new and unique ideas that are appropriate to the circumstances and assumptions of the problem. Thus, with the smoothness from the possible exploitation, considering the problem in many aspects together with the old knowledge connection, forming numerous solutions to the problem, yet depending on the fluency of each student so that learners can choose a various solution.

Flexibility is a thinking mind that recognises the nature of things, the flexibility from one intellectual activity to another, from one problem to another; flexibly apply analysis, synthesis, comparison in activities. They need to know how to change methods to suit the conditions and circumstances, not to be stereotyped and restricted to the existing ones; quickly adjust the thinking direction when encountering obstacles and find new solutions to the problem to be solved. Flexibility manifests itself in the ability to resolve problems without stereotypes, machines, the ability to escape the influence of old experiences, methods, ways of thinking, but instead with new methods, creative thinking from the old, thus forming a more effective and optimal solution to the problem.

In the activity of thinking, originality is expressed in the ability to discover new, diverse and unusual things in the process of awareness of things, the ability to relate the assumptions of the problem with related factors, offering unique solutions to problems that are known to others. Thus, with the uniqueness in students' thinking, it is easy to find the relationship between the assumptions and the related knowledge, exploit and analyse the assumptions about the familiar form so that they can apply the knowledge learned in the mathematical solution.

The ability to utilise known knowledge and skills to new situations is an expression of creative thinking. In the process of teaching and learning, this is the ability to show the most, using existing methods to solve new problems, or using knowledge and skills already known in a similar problem. Expression of creative thinking capacity of students in this ability is shown with the content of knowledge and skills learned. Therefore, students know how to transform exercises in an entirely new specific situation about the known, familiar one applies to solve mathematical problems, thereby demonstrating the creativity of students through addressing math problems [11,21].

Students with creative thinking skill will be able to observe and recognise objects at separate angles. Typically, 
when meeting a specific problem, the students occasionally settle according to the method or knowledge they have learned to apply in the problem. It is necessary to establish for students the habit of considering things, recognising specific problems or problems from various aspects through suggestions from teachers or discussions between friends, people around. Thus, revolving around problems need to be solved, that not only form positive habits for students when considering problems to be dealt with but also create excitement, stimulation to find solutions, increase persuasion for issues that need to be solved to handle.

The ability to resolve problems in numerous ways demonstrates the creativity of learners $[10,23]$. One of the most necessary abilities for the development of creative thinking capacity is the ability of students' expression when facing problems with objects, relationships that can be considered in many aspects. Standing in front of these problems, the students show their ability to transfer from intellectual activity to other intellectual activities, demonstrating the ability to recognise a mathematical object in many respects. Students can coordinate lots of tools and methods in problem-solving. A highly creative problem requires students to use much detailed knowledge and a variety of methods and solutions. At the same time, it is a combination of knowledge and solution methods, applying their skills and experience with efforts and promoting high creative thinking skill to explore and solve problems.

One of the other mathematical thinking capacities that are widely applied in high schools is critical thinking, a thinking that assists learners in identifying and assessing issues more accurately and objectively $[5,18]$. Nowadays, critical thinking is also one of the centres of interest of educators. Critical thinking is the process of constructing, manipulating, analysing, synthesising or evaluating information collected or generated from observation, experience, reflection, reasoning, or communication in a positive, skilful, intellectually trained way, as a guide for belief and action.

Critical thinking is regarded as the process of evaluating thoughts, evaluating arguments, dealing with problems or making judgments based on gathering and evaluating various information and opinions about specific standards to give the best solution. Critical thinking is the one that considers, relates and evaluates all aspects of a situation or problem. This level of thinking includes skills such as focusing on elements of a problem or difficult situation; collecting and organising information in the problem; remembering and incorporating the information learned. It can be demonstrated that critical thinking is one of the crucial skills of thinking, requiring learners to be proactive in thinking about complicated problems or situations based on thoughts, views and beliefs.

Critical thinking is also conceived and developed through the brain's training process which manifests itself through the ability to analyse reality, review and organise ideas into a system, comparable comparison between similarities and differences, awareness and careful consideration of an object, phenomenon, a combination of proof and reasoning. From there, people use reasoning to increase persuasion, to assess failure think, evaluate arguments, make judgments, results to identify issues more objectively. The ability to think critically in mathematics is manifested by some of the following signs [15]:

(1) The capacity to know observation, review the relationship between the old knowledge and the relationship.

(2) The ability to ask questions to solve problems by themselves.

(3) The ability to find grounds in arguments when addressing problems; assess the rationality of problem detection.

(4) The ability to look at different ideas, have positive scepticism, be able to identify various criteria and apply them to evaluate ideas and solutions; be willing to argue in order to find the best solution.

(5) The ability to make conclusions and address effectively, by the learned knowledge and the criteria are given; know how to evaluate the optimal of problem-solving.

(6) The ability to correct errors when arguing proofs or coping with math problems [16,24].

These signs are closely related, yet the above division is relative because of intersections between these signs. In teaching mathematics, the types of thinking do not exist independently but closely related to each other $[21,24]$. Teaching methods promote the positive nature of students; the more requirements for differentiation the methods meet, the more conditions students have to train and develop their ability to think critically and creatively.

A. Agoestanto et al. [1] studied middle school students' critical thinking skill-based on cognitive style. The sample consisted of four students, of whom two were influenced on the field-independent cognitive type, while the other two were based on field-independent cognitive style. The authors used qualitative and descriptive methods to clarify students' test results. Research outcomes showed that students with field-dependent cognitive pattern had better-thinking ability than students with field-independent cognitive style in such aspects as reasoning, assumption, interpretation and explanation of problems as well as an assessment during the debate.

A study of developing critical thinking of students in mathematics through teaching probability subject in junior high school was conducted by E. Aizikovitsh-Udi \& D. Cheng [2]. The sample included 55 students taking courses on the subject of "probability in daily life", and they were fostered thinking skills from disposition to critical thinking. The effects of the study were observed that students had significantly improved their critical thinking in mathematics thanks to teachers' oriented 
methods of using mathematics in real life, encouraging debate in mathematics contents as well as planning lessons for investigating a mathematical problem.

E. C. Alcantara \& J. M. P. Bacsa [3] implemented a survey of 24 students in public secondary schools in the Philippines on the relationship of the three subjects such as analytical performance, critical thinking skills and problem-solving abilities. The findings indicated that students' mathematical performance was proficient, but the remaining two skills were only above average. Likewise, the level of analytical performance was correlated with these two skills. In addition to the above values, the students encountered some difficulty in skills related to mathematics topics in grade 7 such as resolving problems with sets, finding solutions of equations or inequations with a variable, and explaining data related to column or table charts. Similarly, A. N. Chukwuyenum [4] used experimental designs to influence 195 senior secondary school students in order to assess the impact of creative thinking on mathematical performance. The outcomes revealed that there was a significant difference in scores among experimental groups, but these scores did not depend on the gender of the learners [14]. Also, critical thinking was identified as a means to intensify the students' understanding of mathematical concepts.

Another study of the impact of the modules regarding problem-based learning on critical thinking skill of 68 12th grade students in Indonesia was executed by Firdaus et al. [6]. The experiment was designed to be associated with a group in which to evaluate results based on pre-test and post-test. Students' performance indicated a positive effect of the modules on their ability to think critically in 3 aspects, namely, identifying and interpreting information, analysing information, and evaluating evidence as well as argument.

Another study also using a way of impact related to pre-test and post-test design was carried out by D. Hidayat et al. [9]. In particular, the experimental class had a rigorous mathematical thinking approach, but the control class approached in an expository way. The output of the study confirmed that the experimental class exhibited better creative and critical thinking capacities than the control class.

H. R. Maharani [10] researched on strengthening students' creative thinking ability due to solving a problem in a significant number of ways. Indeed, the author also emphasised that the open-ended problems and their posing had a significant effect on the achievement of creative thinking in children. Instead, the four competencies about fluency, flexibility, originality and careful editing were seen as a means to evaluate this kind of thinking. This group of competencies was also explicitly analysed in the qualitative research of L. Puspitasari et al. [13] on students' creative thinking in addressing arithmetic problems. It was demonstrated that the students who belonged to a group with a stable or low level of mathematics had difficulty in understanding mathematical problems, in particular, they made errors in the process and arranging solving steps because of the limitation of well-structured, systematic and detailed skills.

Another study of reinforcing students' creative thinking thanks to the $5 \mathrm{E}$ learning cycle with the metacognitive technique was made by Runisah et al. [20]. The authors used a quasi-experiment for control and experimental groups, including 173 high school students in Indonesia. The findings were noted that the experimental class impacted by the above cycle exhibited better creative thinking than the control class taught conventionally.

\section{Creative and Critical Thinking, Inequality in the Context of Mathematics in Vietnam}

Vietnam's Mathematics curriculum guarantees consistency, continuous development (from grades 1 to 12), consisting of two closely linked branches, one branch describing the development of content circuits, core knowledge and a branch that describes the development of students' competencies and qualities. At the same time, this curriculum also focuses on continuing with the preschool program and creating the foundation for vocational education and higher education. Moreover, the Mathematics curriculum is expected to aid students in forming and developing mathematical competencies, namely, mathematical thinking and reasoning abilities; modelling competence; problem-solving competence; communication competence; competence in using mathematical tools and means. Some manifestations of critical and creative thinking skills are also clarified in this program.

(1) The task of thinking is relatively proficient, especially in identifying similarities and differences in relatively complex situations and explaining the results of observation.

(2) Use reasoning, inductive and deductive methods to see different ways of resolving problems.

(3) Raise and answer questions when arguing or settling problems. Explain, prove, adjust the implementation solution mathematically.

The definition of inequality presented in Mathematics textbook 10 creates knowledge for students from the old, the known to new knowledge. Additionally, inequality is a reasonably familiar content that students have learned in secondary schools. However, at lower secondary schools, students only get acquainted with the concept of inequality through the triangle inequality mentioned in Geometry $7[19,22]$. The Algebra 10 textbook recalls old knowledge and builds new knowledge of inequality based on old knowledge. In Mathematics 10, Cauchy's inequality is emphasized as it has applications to prove 
other inequalities as well as to find the maximum and minimum values of a function.

In Cauchy's inequality theorem, the textbook only gives the theorem, then proves to confirm the validity of the theorem. With the approach to inequality in the textbook, it is very difficult for students and creates embarrassment for them because they are not persuasive. Based on the teaching methods towards developing mathematical thinking capacity, students need to be impacted on the direction of specific examples. They need to analyse aspects of a problem and results from different angles to generalise and infer the inequality theorem of Cauchy, then prove the theorem to assert its correctness.

Nonetheless, in the formation of knowledge, the consequences of inequality for students are derived from the example of using Cauchy's inequality theorem to prove the problem with two numbers selected as the reciprocal of each other, from the wallet. For example, textbooks form the consequence of Cauchy's inequality; with this approach, students are more comfortable to acquire new knowledge, creating high persuasion for them. This approach is also the method affecting students in building consequent knowledge for students. After forming new knowledge, in order to assess the ability to utilise knowledge into solving exercises, students need to conduct some exercises to apply to each student to complete the assessment.

The three types of exercises associated with inequalities in the 10th-grade math textbook include proving an inequality, finding the maximum or minimum value of a function with the condition of the variable $x$. Proving an inequality is a form of exercise that is mentioned a lot in the textbook and Algebra 10 exercise book. This exercise is a familiar math form for students when they have access to inequalities at the secondary school level. Also, addressing this type of exercise is mainly based on Cauchy's definition of inequality or inequality along with some knowledge at the secondary school level such as constant equations, sums of non-negative or product of numbers; no negative is greater than or equal to 0 . Specifically, with the above problem, it can be seen that the problem assumption has suggested learners about the triangle inequality learned in grade 7 , so to solve the problem comes from a real inequality (triangle inequality) that transforms inequality to prove. For students, solving similar problems requires a stable connection of learnt knowledge with a combination of new knowledge and analytical skills based on ways to prove inequality. Finding the maximum or minimum value of a function is one of the quite tricky task types for students if in secondary schools, finding the minimum value of the function is due to the analysis of the form $A^{2}+M$. In high schools, students have to apply inequalities they have just learned to settle problems.

To use Cauchy's inequality efficiently, learners are required to have sharpness and flexibility, along with a more intuitive and holistic view to find methods for the problem. The construction of several solutions for a problem helps them have many views, stimulate creativity, find new ways to form creative and critical thinking skills in students. In short, inequality is one of the contents that creates lots of difficulties for students in both theory and exercises, involving much other knowledge. Accordingly, dealing with the inequality problem is also quite diverse in methods of solving, hindering students in analysing and finding solutions to the problem. However, proof of inequalities can integrate methods and knowledge to solve problems $[7,17]$. For these reasons, the content of teaching inequality is very suitable for increasing creative and critical thinking skills for students.

\section{Materials and Methods}

\subsection{Participants}

The experiment was conducted at Thot Not High School in Can Tho City, both the experiment class 10B2 and the control class 10B1 were chosen. Conducting the assessment of students' mathematical ability in grades 10B1 and 10B2 was based on the results of the entrance exam to grade 10. This school was in the outskirts of Can Tho City, so students did not have high scores on a math entrance exam.

Table 1. Assessing mathematical competencies of control and experimental classes

\begin{tabular}{|c|c|c|}
\hline Class & Experimental class (10B2) & Control class (10B1) \\
\hline 3.5 & 0 & 3 \\
\hline 4.0 & 4 & 2 \\
\hline 4.5 & 6 & 7 \\
\hline 5.0 & 10 & 8 \\
\hline 5.5 & 6 & 7 \\
\hline 6.0 & 7 & 5 \\
\hline 6.5 & 5 & 1 \\
\hline 7.0 & 2 & 5.50 \\
\hline 7.5 & 5.427 & 1 \\
\hline Medium score & 10 & 1 \\
\hline
\end{tabular}

From the table of statistical results above, it was reported that the input capacity of the two classes was similar. However, in order to assess students' ability more objectively, the hypothesis $\mathrm{H} 0$ was proposed "There is no difference in the capacity of the two classes" and tested by the T-test method. The testing outcomes were as follows: 
Table 2. Descriptive statistics

\begin{tabular}{|c|c|c|}
\hline & $\begin{array}{c}\text { Experimental class } \\
(10 \mathrm{~B} 2)\end{array}$ & $\begin{array}{c}\text { Control class } \\
(10 \mathrm{~B} 1)\end{array}$ \\
\hline Medium score & 5.427 & 5.500 \\
\hline $\begin{array}{c}\text { Standard } \\
\text { deviation }\end{array}$ & 0.9257 & 0.899 \\
\hline
\end{tabular}

Table 3. Average test of control and experimental classes

\begin{tabular}{|c|c|c|}
\hline & F & Sig \\
\hline Levene's & 0.334 & 0.565 \\
\hline T-test & 0.348 & 0.729 \\
\hline
\end{tabular}

Regarding Levene's test, it was said that the variances of the two samples were equal. Based on reading the T-test findings comparing the two averages, because there was Sig. $=0.729>0.05$, the hypothesis was accepted. Hence, the scoring average was the same. More specifically, looking at the results table above, it was indicated that the average of the two classes was approximately the same, so it was believed that the mean of the control and experimental classes were the same with a significance of $5 \%$. Based on that, pedagogical experiments were performed for the experimental class 10B2 in Thot Not High School, Can Tho City.

\subsection{Experimental Content}

There was a proposal to form some mathematical thinking competencies for students through teaching inequality for 10th-grade students. In particular, developing critical thinking and creative thinking skills for them through finding multiple solutions to a problem in order to create conditions for students to have more various solution methods, to view the problem with various aspects from which to bring more objective results to the problem. Besides, it was expected to partly help teachers solve the difficulties in teaching how to support students in acquiring and applying knowledge flexibly and creatively for relatively difficult content such as inequality.

Building and implementing experimental lesson plans based on a system of theoretical knowledge and exercises for inequalities focused on the method of intensifying critical and creative thinking skills for students through solving mathematical problems in a variety of ways which applied to the experimental class and did not influence on the control class. Two experiment learning periods included a theoretical lesson about Cauchy's inequality in the direction of developing critical thinking for students and a lesson of exercises towards promoting creative thinking through resolving mathematical problems in many manners. After each lesson, students were asked to survey to re-evaluate the feasibility of the method proposed.

\subsection{Designing the Lesson Plans}

In the control class, the teacher still taught traditionally; meantime, with two learning periods in the experimental class 10B2, the lesson plans were used and designed with the impact of the teaching method proposed. The teaching process was as follows:

Since inequality was quite a strange knowledge for high school students, and it was mentioned in the secondary school program, it did not go into the content of inequality. For this reason, it could be difficult for students in forming new knowledge as well as employing in solving exercises. Correspondingly, some questions, as well as activities, were built to assist students in absorbing with inequalities better.

Activity 1: Review of knowledge of inequality.

Complete the following table:

\begin{tabular}{|c|c|c|c|}
\hline Number $\mathrm{a}$ & Number b & $(a+b) / 2$ & $\sqrt{a b}$ \\
\hline 2 & 3 & & \\
\hline 1.5 & 4 & & \\
\hline$\sqrt{2}$ & 0 & & \\
\hline 0 & $2 / 3$ & & \\
\hline 5 & 5 & & \\
\hline
\end{tabular}

Ask all students to complete the table and answer some questions suggested by the teacher: What are the characteristics of $a$ and $b$ ? Comment on the relationship between $(a+b) / 2$ and $\sqrt{a b}$, when "=" occurs? After students complete the table and answer the above question, comment and formulate knowledge "Cauchy's inequality theorem".

This approach is an activity of forming knowledge for students from practical examples, thus verifying the results to form new knowledge. It gives students a theoretical approach quite simple and more comfortable to understand than forming for them with their critical skills, from the concrete problem to the general one. To confirm the theorem above, the teacher guide students to conduct the theorem-proof in the general form with two numbers $a$ and $b$.

Activity 2: Applying the knowledge students have just applied to address the problem "For $a>0$. Prove that $a+1 / a \geq 2$. Find different solutions". To deal with this problem, students can find out the solutions in two simple ways, including equivalent transformations and the use of Cauchy's inequality.

In the activity 2 , the teacher influences the creative thinking method in solving problems in several ways through some questions that recall learnt knowledge for students applying new knowledge to resolving problems, stimulating searching skills, and creating other solutions to the problem. From the answer to the problem, students comment on their application of new knowledge in coping with problems. From there, let them consider and find out the characteristics of the above problem that the sum of two inverse numbers is typically higher than or equal to 2 by the suggested questions from the teacher for them to take. Based on some specific examples to verify the above conclusion, the teacher comment and admit that it is a 
consequence. This consequence can be applied to mathematical exercises to find the maximum and minimum values of the function instead of using the old methods learned. Thus, it is awaited to form new knowledge for students by the method of critical thinking, from concrete, practical exercises to conclusions in general form.

In order to inform similar knowledge about geometric meanings of inequality or extending inequality, lesson plans are built to accord with the formation method for students about critical thinking, create habits for students in verifying as well as acknowledge a new definition, theorem or consequence. Besides, forming critical thinking for learners not only creates excitement and curiosity but also gives students access to knowledge. The new formula quickly becomes more persuasive, more objective. In the second period, as it is a practice one, students mainly use newly learned knowledge to solve math problems with the impact of creative thinking methods through solving problems in a large number of ways that lesson plan prepared.

In practice period, the students are offered three types of exercises corresponding to the ones presented in the textbook \& the Algebra 10 exercise book, to consider and assess the skills to apply the knowledge learned in solving math problems and the methods that they use in the inequality exercises. At the same time, it is considered to assist them in raising creative thinking through addressing problems in lots of ways with the guidance and suggestions of teachers. The process of teaching and practising inequality is as follows.

Activity 1: Proving inequalities

Problem 1. Prove the following inequalities in different ways $x, y \geq 0$.
(a) $x^{2}+y^{2} \geq 2 x y$
(b) $x^{3}+y^{3} \geq x^{2} y+x y^{2}$
(c) $x^{4}+y^{4} \geq x^{3} y+x y^{3}$

Through the above problem, some questions are mentioned: "What comment do you have about the characteristics of the above inequalities? From there, can you predict the outcome of the problem related to $x^{5}+y^{5}$ ? Generalise the problem involved with $x^{n}+y^{n}$, where $n>1 "$.

Activity 2: Find the maximum value of the function $y=f(x)$.

Problem 2. Find the maximum value of the following functions with $0 \leq x \leq 1$ :
(a) $y=f(x)=x(1-x)$
(b) $y=f(x)=x(1-x)^{2}$
(c) $y=f(x)=x(1-x)^{3}$

Similar to activity 1 , some questions are raised: "What comments do you have about the characteristics of the functions and the results of each function found? From there, you should predict the answer to the problem involving with $x(1-x)^{4}$, generalise the problem $x(1-x)^{n}$ where $n>1$.

Activity 3. Find the minimum value of the function $y=f(x)$.

This activity is built similar to activity 2 , in order to test the ability to apply the learned knowledge into the math problem of students. This activity was converted into the homework for them, in addition to assessing the level of the use of the knowledge they have just learned in solving math problems, can stimulate the ability to explore and create other solutions.

\subsection{Designing Survey Forms}

At the end of the experimental process, it was aksed for students in both experimental and control classes to do the same post-test. Additionally, in order to make a more objective assessment of the methods proposed and to learn more about the students' perception of the method, a survey was conducted through questionnaires about learning periods as well as critical thinking skills for the experimental class. For a post-test through solving problems in several ways, they were for both experimental and control classes.

Problem 1: Given the function $y=f(x)=(x-1)(3-x), 1 \leq x \leq 3$.

(a) Prove that the function has the maximum value equal to 1 by many different solutions.

(b) For the function, $y=g(x)=(x-a)(b-x), a \leq x \leq b \quad a, b$ are real numbers. What prediction do you have about the maximum value of the function given? Explain.

Problem 2:

(a) Solve the following problem in several ways: Given $a, b, c>0$. Prove that $\frac{a+b}{c}+\frac{b+c}{a}+\frac{c+a}{b} \geq 6$.

(b) Of the solutions you presented, which one do you like best? Why?

Pre-analysis of Problem 1

This exercise is a mathematical form using the Cauchy's inequality at a low level of application, so students can easily recognise if viewing two polynomials $x-1$ and $3-x$ is non-negative numbers $a$ and $b$. For this problem, three solutions can be presented, such as using Cauchy's inequalities directly, using seven constant equations in junior high schools and utilising Parabol's vertices. Question b is designed to assess students' critical thinking skill as well as the ability to generalise the problem.

Pre-analysis of Problem 2

This problem makes it difficult for students to utilise the Cauchy's inequality since applying to the three above equations is not simple. Three solutions to this problem are also predicted, and they are associated with the utilisation 
of Cauchy's inequality. However, each solution requires a more complex transformation than problem 1. For this reason, these solutions require students to have thought in separating each formula and accompanied by the perspective of recognising the problems with the theory proficiently. This problem expects to evaluate the creativity in the learners' solution, in particular, they need to show analysis, synthesis and comparison in order to provide a reasonable solution and avoid making mistakes in deductive. Question $\mathrm{b}$ of problem 2 addresses the ability of students' self-assessment of solutions; in particular, they show critical thinking skill for clarifying the advantages and limitations of each solution.

\section{Results and Discussion}

\subsection{Results in Learning Periods}

Some findings were recorded in the learning periods. When the teacher asked students to present a specific solution for each item in the above problem, only a student solved the item a from changing the function to the form $A^{2}+M$, and majority of students were not easy to change in items $\mathrm{b}$ and c. Correspondingly, it was found that without the support of Cauchy's inequality, finding the maximum and minimum values of the problem became difficult. In activity 3 , finding the minimum value of the function was built similar to that inactivity 2 . In order to test the ability to apply the learned knowledge into the mathematical problem of students, this activity changed into the homework for students. In addition to assessing the level of applying the knowledge they had just learned in solving math problems, they stimulated the ability to explore and create other solutions.

Thus, through the solutions that students presented in the activities, the initial formation for students with analytical abilities, skills to consider problems related to ancient knowledge as well as find interrelated factors involved with the construction of problems identified. Nevertheless, students were not flexible in terms of transforming equations to employ the knowledge they had just learned (Cauchy's inequality), students were confused in utilising Cauchy's inequality in items b and c. Besides, they expressed through the student's preference to choose to use equivalent transformations to prove the right inequality instead of using Cauchy's inequality learned. Since then, it was seen that inequality was quite a problematic content, requiring a combination of skills and methods proficiently and flexibly to apply well the knowledge learned into the problem-solving. Furthermore, it was concluded that the ability of critical thinking of students was formed quite well through consideration of recognizing the characteristics of the problem as well as finding out the rules of the results of each problem.

\subsection{Survey Results after Learning Periods}

To evaluate the methods impacted on the lesson for students after the lesson, the opinions of 41 students in the experimental class about the approach, the interest as well as the skills of critical thinking, the ways students judged by the lesson plans were collected.

Based on the above survey outcomes, it was observed that after the employment of the critical thinking capacity for teaching inequality through pre-designed lesson plans, the effects were entirely satisfactory. Through the teaching periods, 17 students thought that inequality content was difficult to comprehend; meanwhile, 19 students received the knowledge regularly. Regarding the attitude towards the lesson, the 24 students $(58.8 \%)$ felt very interested or interested in the lesson of inequality; only a student (2.4\%) felt uninterested. To find an answer to the question about the skills learned through lessons, they emphasized the following skills, namely, predicting results, assessing knowledge, analyzing and generalising. Alternatively, on the question of applying skills to solve problems related to inequality shortly, they alluded the following skills in ascending order of degree such as analysis, a generalization of problems, assignability of new problems to the familiar problems and assessment of the knowledge gained regarding the problems. For the final question about predicting its outcome $x(a-x) \leq$ ?, where $0 \leq x \leq a, 38$ students $(92.7 \%)$ gave the exact answer as $a^{2} / 4$.

It was documented that the impact of the activities of teaching inequality was sufficient for both teachers and students. Moreover, after the learning periods, students learnt some skills about predicting results, abilities to analyse problems, assess knowledge and generalise problems, in which most students effectively followed analytical capacities. The formation of some skills in students created favourable conditions for them to apply in solving problems of inequality in an effective way.

\subsection{Survey Results Related to the Performance of Creative and Critical Thinking Skills in Problem-Solving from Experimental and Control Classes}

Through the survey of students in the experimental and control classes and based on implementing the teaching methods towards developing creative and critical thinking abilities, the following outcomes were obtained:

Table 4. Statistics of ways students performed

\begin{tabular}{|c|c|c|c|c|}
\hline Numbers of ways & 0 & 1 & 2 & 3 \\
\hline Class & 3 & 4 & 32 & 2 \\
\hline
\end{tabular}




\begin{tabular}{|c|c|c|c|c|}
\hline class & $7.3 \%$ & $9.8 \%$ & $78 \%$ & $4.9 \%$ \\
\hline \multirow{2}{*}{ Control class } & 2 & 25 & 8 & 0 \\
& $5.7 \%$ & $71.4 \%$ & $22.9 \%$ & $0 \%$ \\
\hline
\end{tabular}

Through the above results, it was indicated that the rate of students solving two ways in the experimental class was superior to that of the control class (32:8). In contrast, the rate of students in the control class addressed the problem in one way more than that of the experimental class $(25: 4)$. Specifically, in the experimental class, the number of students who solved the problem in one way was 4, accounting for $9.8 \%$, the number of students who resolved in two ways was 32 , accounting for $78 \%$, but three students (7.3\%) could not cope with the problem. Only two students gave the solutions to the problem in 3 ways, accounting for $4.9 \%$. For the control class, the rate of students solving in 2 ways was $22.9 \%$, lower than that of the experimental class. Instead, the majority of students who could do it in one way accounted for $71.4 \%$ of the total of 35 students. Especially in the control class, no student was settling the problem in 3 ways.

With the impact of the method of teaching mathematics through strengthening some mathematical thinking capacities, most students in the experimental class partly learnt quite well. They resolved problems from analysis, recognition, and consideration of the problem in many respects, use of the known knowledge in solving problems, and establishment of a solution to the problem. This result was shown through the above table; the ratio of students with two solutions in experimental class was more than that in the control class because students only learnt with the support of the teaching method proposed in only two learning periods. Nonetheless, to evaluate the level of using old knowledge or newly learned knowledge in settling math problems, it was essential to making statistics of the ways students used in resolving math problems through the table below.

Table 5. Statistics results of solution students chose to perform

\begin{tabular}{|l|l|l|l|l|l|}
\hline \multicolumn{2}{|c|}{ Ways of solving } & 0 & Way 1 & Way 2 & Way 3 \\
\hline $\begin{array}{l}\text { Experimental } \\
\text { class }\end{array}$ & $\begin{array}{l}\text { Number of } \\
\text { students }\end{array}$ & 4 & 37 & 25 & 9 \\
\hline Control class & $\begin{array}{l}\text { Number of } \\
\text { students }\end{array}$ & 2 & 33 & 6 & 2 \\
\hline
\end{tabular}

From the survey results, it was reported that the percentage of students in both control and experimental classes using the way one accounted for the majority, individually up to $37 / 41$ students in the experimental class and 33/35 students in the control class (way 1: using Cauchy inequality). This outcome showed that the ability to apply the knowledge just learned in solving math problems of students in both classes was quite good, partly as this was a newly learned knowledge. Consequently, students typically thought analytically in the direction of applying the newly learned knowledge, instead of associating old knowledge. Besides, for the experimental class, there were 25 students chose to solve the way 2 (using constant equations), but this rate of the students in the control class was quite low. Although this was a mathematical exercise to find minimum and maximum values at secondary school, students were done with the application of 7 constant equations. This method was also a reasonably simple solution, and students only needed to master the seven constant equations to analyse the problem put on the square of a difference or a sum with a remainder $M$ (parameter), from which the maximum and minimum values were able to be found. Thus, it was assumed that considering the problem in many aspects as well as linking the ancient knowledge into solving problems in the control class had not been stimulated to promote in the right way. However, the way 3 , which had a few students using in the above math problem was not strange for them. Correctly, nine students in the experimental class and two students in the control class implemented. The solution was based on a parabolic graph with the maximum value to find equal to the vertical value of the parabola coordinates was one of the knowledge learned in Chapter 2 of Algebra 10.

For item $b$, the function $y=g(x)=(x-a)(b-x)$, where $a \leq x \leq b ; a, b$ were real numbers that required students to predict the maximum value of the function. This exercise was one of the questions designed to evaluate the ability of students to think critically through generalising the problem. For the experimental class, there were 30 students (accounting for 73.2\%) having the correct prediction of the maximum value of the function, while the control class had $48.6 \%$ of students correctly predicting the maximum value of the function in the generalised form $(b-a)^{2} / 4$. It was believed that the critical thinking capacity in the experimental class was better formed since students apply the learnt knowledge into the prediction of the general form. However, in the control class, the generalisation of the problem in each student was still quite low. If students in the control class mainly relied on the Cauchy's inequality to predict the answer to the problem in general form, the students in the experimental class forecasted the results determined from changes of two numbers $a$ and $b$. 
Table 6. Statistics of students choosing the solution and students solving correctly in each way (in Problem 2)

\begin{tabular}{|c|c|c|c|c|c|}
\hline & Ways of solving & 0 & 1 & 2 & 3 \\
\hline \multirow{2}{*}{$\begin{array}{l}\text { Experimental } \\
\text { Class }\end{array}$} & Number of students & $\begin{array}{c}0 \\
0 \% \\
\end{array}$ & $\begin{array}{c}27 \\
65.9 \% \\
\end{array}$ & $\begin{array}{c}5 \\
12.2 \% \\
\end{array}$ & $\begin{array}{c}9 \\
21.9 \% \\
\end{array}$ \\
\hline & $\begin{array}{l}\text { Number of students } \\
\text { with correct solution }\end{array}$ & & $\begin{array}{c}22 \\
81.5 \% \\
\end{array}$ & $\begin{array}{c}5 \\
12.2 \% \\
\end{array}$ & $\begin{array}{c}9 \\
21.9 \% \\
\end{array}$ \\
\hline \multirow{2}{*}{$\begin{array}{l}\text { Control } \\
\text { class }\end{array}$} & Number of student & $\begin{array}{c}16 \\
45.7 \% \\
\end{array}$ & $\begin{array}{c}19 \\
54.3 \% \\
\end{array}$ & $\begin{array}{c}0 \\
0 \% \\
\end{array}$ & $\begin{array}{c}0 \\
0 \% \\
\end{array}$ \\
\hline & $\begin{array}{l}\text { Number of students } \\
\text { with correct solution }\end{array}$ & & $\begin{array}{c}13 \\
68.4 \% \\
\end{array}$ & $\begin{array}{c}0 \\
0 \% \\
\end{array}$ & $\begin{array}{c}0 \\
0 \% \\
\end{array}$ \\
\hline
\end{tabular}

Through the survey results for the problem 1 and based on developing some mathematical thinking competencies for students in the experimental class, they learnt several skills such as analysing a problem, finding the connection between knowledge, knowing the problem assumptions, looking. Also, they had skills of considering the problem in many respects, building lots of solution methods, predicting the problem answers through specific problems, thus creating interest in learning mathematics as well as solving math problems about Cauchy's inequalities in students. Accordingly, the methods that were impacted on teaching were effective.

According to Table 6, the findings revealed that the rate of students solving correctly in the experimental class was quite high, and 14 students in this class solved the problem 2 in two or three ways with correct solutions. Twenty-two students settled correctly according to way 1 , accounting for $81.5 \%$ and $18.5 \%$ of students gave the wrong solutions. Additionally, most of them addressed this problem due to using Cauchy's inequality. For the control class, there were $54.3 \%$ of students resolving the problem in a way, but $68.4 \%$ of them who had the right solutions. Especially in the control class, there was $45.7 \%$ of students who could not deal with the type of exercise. When surveying this problem, it was quite surprised with the results of the analysis since no students in the control class had addressed the problem in two or more ways, most of the solutions which students used were related to Cauchy's inequality. This finding showed that the students in the class were not impacted on the methods of teaching mathematics according to the designed lesson plans, so their ability to think creatively and critically was also limited, leading to them not succeeding in the requirements of the problem.

As for the result of item $b$ in the problem 2, the majority of students rated Cauchy's use of inequalities for the two nonnegative numbers as the other methods that required more inference led to difficulties in the process of transforming the terms. Cauchy's way of transforming inequalities for three non-negative numbers was less popular with students in mathematics classes; therefore, that was the obstacle they applied to the problem of proving the inequalities.

\section{Conclusions and Suggestions}

Experimental results indicated that the teaching methods influenced the experimental class brought significant effectiveness in terms of mathematical thinking for students. Accurately, the students performed well to solve the two problems in the post-test, then their critical and creative thinking skills were strengthened through the teaching activities. Solving problems in several ways formed students high creative thinking skills from analysing problems, searching related knowledge to consider, recognising problems in many respects, giving students calculation curiosity, discovery, search for different solution methods. Besides, based on building many methods to resolve a problem, training self-study ability, students always asked themselves questions and group for themselves and researched to find answers before the problem-posing. At the same time, there was a connection between new knowledge and old knowledge in the brain of students to find the relationship between that knowledge and the problematic assumptions in order to build methods of addressing problems. This result is also mentioned in the study of Maharani [10].

In these solutions, students had difficulty in selecting related knowledge to form the knowledge that was necessary to be proved because this required being diligent, finding garlic, and identifying mathematical forms of similar nature. Specifically, it requested students to have a firm knowledge of equality. Moreover, they needed to see the relationship between the square equality of a difference and the sum of two cubic equalities, derived from the square equality equation of a difference combined with necessary skills such as multiplying (dividing) two sides by the same amount to give a proof $[7,19]$. From here, the formation for students skills of linking old knowledge with new knowledge was realized.

For solutions derived from a real inequality, choosing old knowledge in this solution was quite tricky for students, since students had to master the knowledge of extended inequality for the three numbers attached to the choice of the appropriate three terms to bring out new knowledge. In this solution, they were not only formed the skills for students to relate old knowledge to new knowledge but also enhanced thinking skills about expanding inequality, the flexibility in analysing and selecting suitable terms by the problem requirements.

With the problems in the experiment, the participants were also proposed to build some methods to solve the 
problem in order to build the skills of problem analysis, evaluation, searching related knowledge, the relationship between knowledge. Knowing the knowledge with the assumptions, recognising the problem in many different respects, from which it was possible to build solutions to address the problem more convincingly. At the same time, they create excitement for students, stimulate to be able to explore, learn, create from the known solution method into a new unique solution method. For instance, in this solution, students mainly formed analytical skills, exploration abilities, and discovered the relationship between the knowledge, the known solution methods in solving mathematical problems. This outcome is similar to the one in the study of Rasiman [14].

However, the fact showed that the students in the two classes were easy to commit errors when finding out the answers to the above types of exercises. Correspondingly, the activities resulted in the formation of critical thinking capacity for students through self-examination of problems such as analysis, finding the relationship between assumption with learned knowledge, assessing the correctness of the solution method. Also, adjusting the solutions assisted students in overcoming mistakes and dealing with the problems better. Thus, to form creative and critical thinking skills for students for each type of exercises mentioned in math program 10 , in addition to the impact of teaching methods, they are necessary to know more about the solution methods. In each problem, it is used interweaving between the solution methods together, creating a variety for solving the problem. Thereby, students are simpler in finding the relationship between the related knowledge and the problem assumption, considering the problem in many aspects, building novel solutions that are better applied. Learned knowledge creates the premise to develop mathematical thinking capacity in each student individually.

Some of the implications, as well as suggestions for the enhancement of students' creative and critical thinking skills, are drawn from the findings of the experiment. First, the teachers train students to apply the knowledge and skills they know to deal with mathematical problems, creating excitement for students. To apply knowledge efficiently and known skills in solving problems, the formation of prejudice for students must be done flexibly and systematically; presenting knowledge that is easy to understand and absorb. In comparison with the theoretical period, more exercises are built. If the theoretical lesson must be formed for students to understand and remember about the concepts, theorems, consequences, then the lesson requires skills to use fluently the relevant knowledge, and transform accordingly with a situation, in which the problem needs to be solved. At the same time, creating excitement for students in learning mathematics from visual examples that are related to reality. This approach makes it easy for students to acquire and stimulate their ability.
Next, teachers practice analytical skills; in particular, they need to look at problems in many diverse aspects, comment and evaluate to give optimal solutions for the problem $[19,23]$. When dealing with a problem, it is first necessary to analyse the problem in search of relevant knowledge associated with the skills to build a solution to the problem. However, problem-solving can be done with lots of different solutions in order to choose the best solution that suits the problem. In teaching mathematics, too, when giving a problem that requires students to solve, it is essential to select the problem with several solutions, yet, the construction of the problem has to be suitable to the capacity of each student individually to promote more creative ability of each student $[9,10,13]$.

Additionally, students frequently face lots of difficulties in learning mathematics and solving mathematical problems [3]. To cope with a problem, in addition to applying the knowledge learned in the problem, math skills play a vital role. As a result, addressing a problem in lots of ways is not simple, when students find the solution to a problem, they are often delighted with the answers they have found. However, most of them never find another solution to the problem they found. It is considered as one of the causes leading to a lack of creative thinking in students. Resolving problems in several ways gives students and teachers an objective outcome, thus increasing the persuasiveness of the problem. Besides, from the habit of training to settle problems in many manners, it was beneficial to form well-developed students' creative thinking ability, ability to reason problems in different directions in various situations. Since then, when encountering a problem, students are always looking for solutions as well as looking for diverse solutions with lots of aspects in order to find the relevance of the problems as well as the assumptions of the problem so that students can find the solution quickly, briefly and effectively. Through that, it is partly effective to form students' perseverance, creativity in learning, and problem-solving skills as well as the abilities to find the solutions in various directions in each situation.

Forming creative thinking capacity for students to add excitement, passion and stimulate the process of searching and discovering subjects [20]. Nonetheless, resolving a problem with several solutions if not well developed, can lead to negative trends for both teachers and students. Accordingly, teachers are indispensable to regularly build similar questions with the guided problems in order to train students with the problems solved in different ways, also; initially, teachers can build questions and suggestions for students with many respects. Mainly, students are demanded to take hard to train learning, analytical practice skills as well as recognise problems with many various angles and expertly use the learned knowledge, self-supplementing corrupted knowledge [8]. For this reason, dealing with problems in a variety of 
ways needs to be adequately developed and reasonably for each type of exercise, thus avoiding unnecessary abuse and little effect on learning.

In order to grow critical thinking skills for students, teachers need to practice the ability to consider and view problem-specific words, details in the whole $[2,6,14]$. When facing a situation or a problem, students are required to analyse the assumptions related to public knowledge to find solutions to problems. Nevertheless, with the same problems and situations from previous situations, students can give a similar solution for those situations or problems. Specifically, in mathematics, from solving similar exercises, it is possible to generalise the problem to give a general method to address that type of exercise. In order to train and promote the ability to generalise the problem, teachers need to design activities as well as problems that suit each individual's capacity and practice diligence and patience in finding the solutions to the problems.

Furthermore, teachers provide chances for students to get the habit of self-solving challenges and necessary thinking manipulations. The practice of thinking manipulations such as analysis, synthesis and comparison is one of the critical factors to train critical thinking. For this reason, the manipulations of thinking must be trained for students to understand in the interwoven direction, mutual support each other rather than training each operation separately. Also, teachers need to support their students in understanding how to solve mathematics, select appropriate knowledge, and build solutions that are consistent with knowledge. A reasonably necessary skill in training critical thinking which is to practice the habit of creating challenges for themselves is asking questions. In learning mathematics, in order to understand and solve problems in a proficient way, students find it necessary to set themselves before the questions and contact knowledge, research documents to find answers to the challenges posed.

In summary, creative and critical thinking skills are quite essential to train students in teaching mathematics. With expressions in the attitude of being willing to argue, assess knowledge, correct mistakes and accepting challenges, it is necessary to create students' confidence habits before making arguments, solving problems and challenges set out. Also, in order to promote the above habits for students, teachers are petitioned to listen, absorb ideas, encourage them to express their views, whether they agree or disagree before a particular point of view. Consequently, teachers are also expected to design teaching and learning activities or learning tasks to facilitate the promotion of creative and critical thinking skills for students, aiding them incorrectly identifying the process of evaluation, affirmation, and particular views $[8,23]$.

\section{REFERENCES}

[1] A. Agoestanto, YLSukestiyarno \& Rochmad. Analysis of Mathematics Critical Thinking Students in Junior High School Based on Cognitive Style, Journal of Physics: Conference Series, Vol.824, 1-6, 2017.

[2] E. Aizikovitsh-Udi, D. Cheng. Developing Critical Thinking Skills from Dispositions to Abilities: Mathematics Education from Early Childhood to High School, Creative Education, Vol.6, 455-462, 2015.

[3] E. C. Alcantara \& J. M. P. Bacsa. Critical Thinking and Problem-Solving Skills in Mathematics of Grade-7 Public Secondary Students, Asia Pacific Journal of Multidisciplinary Research, Vol.5, No.4, 21-27, 2014.

[4] A. N. Chukwuyenum. Impact of Critical thinking on Performance in Mathematics among Senior Secondary School Students in Lagos State, IOSR Journal of Research \& Method in Education, Vol.3, No.5, 18-25, 2013.

[5] G. Dam \& M. Volman. Critical thinking as a citizenship competence: teaching strategies, Learning and Instruction, Vol.14, 359-379, 2004.

[6] Firdaus, I. Kailani, M. N. B. Bakar \& Bakry. Developing Critical Thinking Skills of Students in Mathematics Learning, Journal of Education and Learning, Vol.9, No.3, 226-336, 2015.

[7] K. Hemmi, C. Lofwall. Why Do We Need Proof, Proceedings of CERME 6, January 28th-February 1st 2009, Lyon France (C) INRP 2010, 201-210, 2009.

[8] S. Mahanal, S. Mahanal, I. D. Sumiati, T. M. Sari \& N. Ismirawati. RICOSRE: A Learning Model to Develop Critical Thinking Skills for Students with Different Academic Abilities, International Journal of Instruction, Vol.12, No.2, 417-434, 2019.

[9] D. Hidayat, E. Nurlaelah \& J. A. Dahlan. Rigorous Mathematical Thinking Approach to Enhance Students' Mathematical Creative and Critical Thinking Abilities, International Conference on Mathematics and Science Education, No.895, 1-6, 2017.

[10] H. R. Maharani. Creative Thinking in Mathematics: Are We Able to Solve Mathematical Problems in a Variety of Way?, International Conference on Mathematics, Science, and Education, 120-125, 2014.

[11] E. L. Mann. Creativity: The Essence of Mathematics, Journal for the Education of the Gifted. Vol.30, No.2, 236260, 2006.

[12] M. K. Minter. Thinking Concept Reconstructed, Contemporary Issues in Education Research, Vol.3, No.8, 33-42, 2010.

[13] L. Puspitasari, A. In'am \& M. Syaifuddin. Analysis of Students' Creative Thinking in Solving Arithmetic Problems, International Electronic Journal of Mathematics Education, Vol.14, No.1, 49-60, 2019.

[14] M. Pd. Rasiman. Levelling of Students' Critical Ability in Solving Mathematics Problem Based on Gender Differences, International Journal of Education and Research, Vol.3, No.4, 308-318, 2015. 
[15] Rochmad, A. Agoestanto \& M. Kharis. Dahlan. Characteristic of Critical and Creative Thinking of Students of Mathematics Education Study Program, No.983, 1-4, 2018

[16] Rochmad, M. Kharis, A. Agoestantoa, M. Z. Zahida \& Mashuri. Clark. Misconception as a Critical and Creative Thinking Inhibitor for Mathematics Education Students. Unnes Journal of Mathematics Education, Vol.7, No.1, 5762, 2018.

[17] I. Rofiki1, T. Nusantara, Subanji \& T. D. Chandra. Reflective Plausible Reasoning in Solving Inequality Problem, IOSR Journal of Research \& Method in Education, Vol.7, No.1, 101-112, 2017.

[18] E. E. Rohaeti. Critical and Creative Mathematical Thinking of Junior High School Students. Educationist, Vol.4, No.2, 99-166, 2010.

[19] A. H. Rosyidi, A. W. Kohar. Student Teachers' Proof Schemes on Proof Tasks Involving Inequality: Deductive or Inductive?, MISEIC, No.947, 1-9, 2018.

[20] Runisah, T. Herman \& J. A. Dahlan. The Enhancement of Students' Creative Thinking Skills in Mathematics through The 5E Learning Cycle with Metacognitive Technique, International Journal of Education and Research, Vol.4, No.7, 347-360, 2016.

[21] S. Sanders. Critical and Creative Tinkers in Mathematics Classrooms, Journal of Student Engagement: Education Matters, Vol.6, No.1, 19-27, 2016.

[22] A. Sierpinska, G. Bobos \& A. Pruncut. Teaching absolute value inequalities to mature students, Educational Studies in Mathematics, Vol.7, No.3, 275-305, 2011.

[23] H. F. Su, F. A. Ricci \& M. Mnatsakanian. Mathematical Teaching Strategies: Pathways to Critical Thinking and Metacognition, Journal of Research in Education and Science (IJRES), Vol.2, No.1, 190-200, 2016.

[24] K. Ulger. The Relationship between Creative Thinking and Critical Thinking Skills of Students, H. U. Journal of Education, Vol.31, No.4, 695-710, 2016. 